Etnográfica

Revista do Centro em Rede de Investigação em

Antropologia

vol. 25 (3) | 2021

Vol. 25 (3)

\title{
Reassentar e indenizar: formas de governo no contexto da implantação da usina hidroelétrica de Belo Monte, em Altamira, Brasil
}

Resettlement and indemnity: forms of governance through the implementation of the Belo Monte Hydroelectric in Altamira (Brazil)

\section{Paula Lacerda}

\section{(2) OpenEdition}

\section{Journals}

\section{Edição electrónica}

URL: https://journals.openedition.org/etnografica/10328

DOI: 10.4000/etnografica. 10328

ISSN: 2182-2891

\section{Editora}

Centro em Rede de Investigação em Antropologia

\section{Edição impressa}

Data de publição: 1 outubro 2021

Paginação: $729-749$

ISSN: 0873-6561

\section{Refêrencia eletrónica}

Paula Lacerda, «Reassentar e indenizar: formas de governo no contexto da implantação da usina hidroelétrica de Belo Monte, em Altamira, Brasil», Etnográfica [Online], vol. 25 (3) | 2021, posto online no dia 28 outubro 2021, consultado o 09 janeiro 2022. URL: http://journals.openedition.org/etnografica/ 10328 ; DOI: https://doi.org/10.4000/etnografica.10328

\section{(c) (†) \&}

Etnográfica is licensed under a Creative Commons Attribution-NonCommercial 4.0 International License. 


\section{Reassentar e indenizar: formas de governo no contexto da implantação da usina hidroelétrica de Belo Monte, em Altamira, Brasil}

\section{Paula Lacerda}

O presente artigo é resultado de pesquisa etnográfica realizada junto a moradores que desde 2009 vivenciam os efeitos da implantação da Usina Hidroelétrica (UHE) de Belo Monte, em Altamira, cidade localizada no sudoeste do Pará, na Amazônia brasileira. Nesse trabalho, tomo a UHE Belo Monte como um projeto de desenvolvimento e analiso as formas de governo a partir de um de seus principais instrumentos: as indenizações. O argumento central do texto é o de que em uma cidade fundada e refundada sob o marco do "desenvolvimento", reassentar e indenizar são ao mesmo tempo promessas associadas à garantia de direitos e bem-estar social e práticas pouco compreensíveis que ensejaram sentimentos como o de inferiorização, inadequação e humilhação por parte da população cujas vidas, experiências e cotidiano foram afetados por tais transformações.

PALAVRAS-CHAVE: Amazônia, práticas estatais, indenizações, desenvolvimento, direitos humanos, Belo Monte

Resettlement and indemnity: forms of governance through the implementation of the Belo Monte Hydroelectric in Altamira (Brazil) - This article is the result of an ethnographic research performed with men and women who, since 2009, have been experiencing the effects of the implementation of the Belo Monte Hydroelectric, at the city of Altamira, located in the southwest of Pará in the Brazilian Amazon. In this work, I approach the hydroelectric plan as a development project and analyze the forms of governance based on its main instrument: indemnities. The text's main argument is that in a city repetitively (re)founded under the framework of "development", the acts of resettlement and indemnification at the same time become promises associated with the guarantee of rights and social welfare and practices that arouse feelings of inferiority, inadequacy and humiliation between the people of the city affected by the project.

KEYWORDS: Amazon, state practices, indemnity, development, human rights, Belo Monte

LACERDA, Paula (lacerdapaula@gmail.com) - Universidade do Estado do Rio de Janeiro, Brasil 


\section{ALTAMIRA, UMA CIDADE AMAZÔNICA}

Ao longo das décadas de 70 e 80, a cidade de Altamira, no sudoeste do estado do Pará, na Amazônia brasileira, esteve no noticiário nacional e internacional por ser a cidade sede ou a capital da BR-230, a Rodovia Transamazônica. A estrada, fruto de um projeto dos governos militares, foi construída entre 1969 e 1974. Seu traçado original permitiria a ligação entre o oceano Atlântico e o oceano Pacífico, o que lhe conferiria o estatuto de "maior estrada do mundo", atravessando outros dois países, o Peru e o Equador. Na época, o projeto, fruto do governo do general Emílio Garrastazu Médici, deveria despertar o espírito nacionalista, porque a estrada iria "integrar" o Brasil para não "entregá-lo" aos interesses estrangeiros, conforme slogan político da época. Além disso, a estrada deveria encantar e orgulhar os brasileiros pela sua grandiosidade - seriam quase cinco mil quilômetros de estrada. A construção da BR-230 inscrevia-se no âmbito do Programa de Integração Nacional (PIN), que concentrou muitas outras iniciativas de infraestrutura e colonização na Amazônia brasileira.

Com a finalização da estrada - apesar de descumprido o planejamento inicial - e a transição para a democracia que ocorreu logo após o governo do general Médici, tornaram-se conhecidas, através de reportagens, as "mazelas" da Transamazônica (Gomes 1975). Pouco depois da abertura da estrada, Altamira ficou conhecida como uma cidade abandonada e decadente, imagem sintetizada na personagem Iracema, do filme Iracema: Uma Transa Amazônica, de 1975, de Jorge Bodanzky. Nas últimas cenas do filme, a personagem principal é deixada na estrada, suja, descalça, sem dentes e com os seios à mostra, enquanto Tião Brasil Grande, um homem branco oriundo do sul do país, segue na estrada com seu caminhão rumo ao estado do Acre, sua nova aposta, também na Amazônia brasileira. A decadência moral e física da personagem que dá título ao filme contrasta com sua pouca idade e com os poucos anos que se passaram desde a abertura da Transamazônica, quando a história se inicia de modo festivo, durante os festejos católicos do Círio de Nazaré, até os momentos finais, que têm como cenário uma estrada sem asfalto, empoeirada, sem sinalização e nenhum veículo transitando por ela.

Anos depois, no final da década de 80, a luta contra a construção da Usina Hidroelétrica de Kararaô em Altamira reuniu o apoio de lideranças internacionais, inclusive do cantor britânico Sting, que ao lado do Cacique Raoni Kayapó inseriu a luta contra as barragens na Amazônia como pauta ambiental e social em nível mundial. Além da visibilidade alcançada pelo encontro de um cantor internacional e de uma liderança indígena em defesa da Amazônia, repercutiu enormemente a imagem da indígena Tuíra Kayapó encostando um facão no rosto de uma autoridade da empresa pública à frente do processo de implementação da hidroelétrica àquela altura. Ao ganharem a imprensa nacional e 
internacional, tais acontecimentos mostraram-se decisivos na interrupção do planejamento de Kararaô, bem como de outros projetos de barramento dos rios da Amazônia.

No final da primeira década dos anos 2000, Altamira ressurge no noticiário nacional e internacional em função da UHE, então batizada como Belo Monte. Diferente da década de 70, em que a estrada representava o progresso e o desenvolvimento, agora era o fluxo do rio e a energia que dele se extrairia que simbolizavam tais aspectos. A grandiosidade segue como dimensão estruturante das narrativas sobre o projeto: a Transamazônica seria a "a maior estrada do mundo", enquanto Belo Monte era "a maior obra do Programa de Aceleração do Crescimento (PAC)" e a "maior hidroelétrica 100\% brasileira". Notemos que tanto a Transamazônica quanto Belo Monte tiveram como epicentro a cidade de Altamira, recorrentemente referida como o "maior município do Brasil", ${ }^{1}$ que por sua vez está localizado na Amazônia, "a maior floresta do mundo".

Ao recuperar os acontecimentos históricos acima descritos, argumento que Altamira, uma cidade média da Amazônia brasileira, é um espaço marcado de tempos em tempos por intervenções públicas e de grande porte, tanto no sentido econômico quanto no sentido social, que apresentam como objetivo declarado o "desenvolvimento" e se baseiam em avaliações que qualificam a região como atrasada, subdesenvolvida, precária. Adoto algumas perspectivas presentes em estudos sobre o (mau) desenvolvimento, como Escobar (1995), Scott (1998) e Ribeiro (2008), reforçando a perspectiva desses autores de que projetos considerados de desenvolvimento estão alicerçados sobre discursos e ideologias de difícil desconstrução.

A proposta de Escobar (1995) de compreender o "desenvolvimento" como um prolongamento das ações do colonialismo faz bastante sentido nas discussões do presente artigo. Segundo o autor, assim como o colonialismo construiu perfis psicológicos e sociológicos dos sujeitos e das coletividades a serem colonizadas, as práticas de desenvolvimento pretendem realizar transformações no espaço e nas subjetividades das pessoas envolvidas, apresentando em seu favor argumentos considerados científicos e racionais. Sigo as perspectivas apresentadas pelo autor, especialmente no que se refere à compreensão das representações que hierarquizam ações e percepções de desenvolvidos e subdesenvolvidos (Escobar 1995: 7), em situações de interação que serão descritas adiante.

Neste artigo, proponho compreender os projetos de desenvolvimento como uma forma de governo e tomo seus principais instrumentos, as indenizações, como procedimento considerado técnico e associado à capacidade de diálogo, à reparação e à justiça social. Associar grandes projetos, como a construção de

l Altamira possui uma área de $159.533,328 \mathrm{~km}^{2}$, o que a torna a maior cidade do Brasil, bastante maior, inclusive, do que vários estados do país. 
hidroelétricas e estradas, à perspectiva de desenvolvimento de regióes classificadas como subdesenvolvidas, distantes e isoladas, é parte fundamental do modo de legitimação de tais projetos. No Brasil, os estudos de Sigaud (1986) reagem às perspectivas apresentadas pelos grandes projetos de desenvolvimento de que os impactos gerados seriam mensuráveis e efêmeros, como se houvesse uma espécie de "acomodação" ao final das intervenções. Com isso, a autora propõe pensar em termos de "efeitos sociais", tomando como ponto de partida a ideia de que os projetos de desenvolvimento são formas políticas a partir das quais se exerce o controle de populações afim de liberar suas terras para o mercado. Como se verá adiante, tal interpretação é adequada ao cenário da cidade de Altamira.

Ao analisar as intervenções no espaço de uma cidade marcada repetidas vezes por projetos considerados de desenvolvimento, priorizo a descrição e análise dos efeitos sobre a parcela da população que teve suas vidas transformadas em múltiplas dimensões, desde o recebimento de uma quantia em dinheiro considerada aquém do valor devido, ou o deslocamento e consequente reassentamento em novos bairros, em moradias diferentes daquelas em que viveram a maior parte de suas trajetórias, até mudanças em sonhos, perspectivas, planos de futuro, ou seja, nos próprios critérios de reflexão e avaliação sobre suas vidas. Assim, esse trabalho pretende dialogar com os campos da antropologia do Estado, do desenvolvimento e dos direitos humanos, estando voltado a pensar as modalidades de governo a partir de suas práticas (os reassentamentos e as indenizações), tal como efetivadas no âmbito de um projeto de desenvolvimento (a UHE Belo Monte), a partir de um território específico (a cidade de Altamira). Dentre os diferentes tipos de indenização praticadas no âmbito da UHE Belo Monte, os reassentamentos foram os mais recorrentes e, por isso, essa análise dedica maior ênfase a eles.

Tomo como inspiração teórica e ao mesmo tempo proposta analítica os conceitos de governo dos vivos, desenvolvido por Foucault (2014), e de gestão de desigualdades, formulado por Souza Lima (2002). No conjunto de aulas proferidas entre 1979 e 1980 no Collège de France, Michel Foucault constrói uma análise do governo em profunda relação com o tema da verdade. Com isso, o autor se afasta da ideia de governo como dominação, e busca compreender os mecanismos e os procedimentos destinados a conduzir a vida de homens e mulheres através de formas específicas de determinação da verdade. Assim, o governo consiste em mecanismos e práticas que direcionam ações, desejos e formas de viver, construindo sujeitos como agentes da manifestação da verdade e da racionalidade. Considerando as especificidades dos processos políticos aqui descritos, compreendo que as formas de governo se concretizam, especificamente, a partir da gestão das desigualdades no sentido explorado por Souza Lima (2002). Para esse autor, processos de formação de Estado carregam de maneira intrínseca modalidades diversas de instauração de desigualdades e 
hierarquias. Enfatizo a perspectiva de que as práticas de gestão de populações ocorrem tanto a partir de "políticas públicas", concebidas como formas racionalizadas de ideias, como também ações que podem ser apreendidas na observação do cotidiano de relações sociais (Souza Lima 2002: 13).

Como se verá nas páginas seguintes, priorizei observar as modalidades de governo a partir das experiências de interlocutores de pesquisa, e também consultei documentos produzidos pela Norte Energia, a empresa responsável pela construção da UHE Belo Monte. Considero que o fato de uma "empresa" ser a responsável pelas profundas transformações no território e na vida de parte significativa da população de Altamira não invalide os aportes teóricos advindos do campo dos estudos sobre as práticas estatais, principalmente porque as formas de governo que serão trabalhadas, ao longo do texto, estão orientadas por parâmetros provenientes da administração pública em nível federal e estadual no que se refere à concessão de licenças e fiscalização, ainda que, como vários analistas já apontaram, a atuação da administração pública nesse processo tenha sido caracterizada por ilegalismos diversos (Cohn 2010; Rojas 2014; Almeida e Marin 2014; Domingues 2017). Além disso, como se verá adiante, a "empresa" responsável pela construção da UHE Belo Monte é formada por empresas públicas, e seu financiamento foi, também, público.

Embora a análise parta de projetos de desenvolvimento incidentes sobre Altamira e procure pensar efeitos através da experiência de seus moradores, não se trata de um caso isolado ou excepcional. Assim, o presente artigo pretende contribuir não apenas com a análise de processos estatais e políticos implementados em Altamira ou na Amazônia brasileira, mas com a reflexão mais ampla sobre práticas e processos de governo em que poder estatal e privado se ampliam e se reforçam. Parto de uma experiência de dez anos de pesquisa em Altamira, sendo que nos últimos quatro anos os interesses de investigação estiveram direcionados para as políticas e as práticas de indenização no contexto da implantação de Belo Monte. Ao longo desses anos, observei um processo de profunda e acelerada transformação territorial e urbana nessa cidade, o que compõe o cenário dessa pesquisa de maneira relevante. Em entrevistas, falas públicas e em muitas outras ocasiões em que realizei trabalho de campo, moradores de Altamira expressam a angústia de viver em uma cidade em que bairros inteiros foram removidos e outros construídos, alterando as formas de viver, morar e circular pela cidade.

Durante o período mais intenso das obras, entre 2012 e 2016, eram frequentes a falta de energia, o desabastecimento de dinheiro nos bancos e a insuficiência de gêneros alimentícios básicos. Mesmo pessoas que não viviam em zonas alagadiças ou consideradas insalubres foram pressionadas pelo alto preço dos aluguéis (que tiveram um aumento de até 300\%), indo viver em zonas precárias e afastadas, onde podiam arcar com os custos do aluguel. Além disso, no período, Altamira enfrentou o vertiginoso crescimento da violência, que 
conferiu à cidade o título de mais violenta do Brasil, com taxa de homicídios três vezes maior do que a média para o país (Cerqueira et al. 2017) e o aumento da violência sexual contra crianças e adolescentes (de 29 casos, em 2009, para 177 casos, em 2012) (Pinho e Oliveira 2013), entre outras situações.

A pesquisa nos Reassentamentos Urbanos Coletivos (RUC) foi iniciada em 2015 e contou com a mediação de interlocutoras de pesquisas anteriores. Os RUC são conjuntos habitacionais construídos para alocar as pessoas removidas de zonas consideradas insalubres. Atualmente, cerca de 24 mil pessoas moram em um dos cinco RUC. Desde então, realizei três viagens de campo com duração média de dez dias, tendo realizado dez entrevistas semiestruturadas e cerca de 20 conversas informais. ${ }^{2}$ Esse material foi ampliado, em 2016, visando alcançar as experiências de moradoras de Altamira que foram indenizadas com uma quantia em dinheiro, não indo viver nos RUC. Além disso, acompanhei reuniões de moradores e participei de caminhadas e outros atos públicos relacionados a Belo Monte, registrando falas, gestos, interações. Em 2015, participei de duas visitas de integrantes do conselho tutelar a bairros que estavam sendo removidos, o Baixão do Tufi e a Invasão dos Padres. De forma complementar e não exaustiva, consultei documentos produzidos pela Norte Energia, empresa responsável pela construção de Belo Monte, e abrigados em seu website ou em outros endereços, em busca de informações sobre as políticas de indenização aplicadas.

O texto que segue está organizado em torno de três aspectos que constituem as formas de governo praticadas em Altamira, tomando as indenizações como eixo central. No tópico "vender o que não tem preço", apresento um breve histórico sobre o tema das indenizações em projetos considerados de desenvolvimento e então busco analisar as práticas de classificação, precificação e (des) valorização aplicadas sobre as casas em que as pessoas viviam. O tópico "os contornos da espera" trabalha a administração racional de algo imaterial, qual seja, o tempo dos moradores de Altamira, ao longo do qual expectativas, planos e sonhos são construídos, reconstruídos, destruídos. No terceiro e último tópico, intitulado "a assimetria que produz a dádiva", aponto o deslizamento do sentido das indenizações, que passam de direito à dádiva, como resultado das assimetrias e das práticas de classificação empregadas. Conforme argumentarei, esse deslizamento alcança contornos ainda mais dramáticos diante de situações em que a assimetria de gênero está também colocada.

2 A pesquisa de campo, realizada em novembro de 2016, contou com a parceria e a colaboração do antropólogo e documentarista Thiago Oliveira, que realizou registros fotográficos e audiovisuais de alguns dos interlocutores da pesquisa. No ano anterior, Thiago Oliveira e Carlos Fausto, antropólogo e professor do Museu Nacional da Universidade Federal do Rio de Janeiro, Brasil, produziram material audiovisual ao qual tive acesso. Agradeço a ambos pela gentileza do compartilhamento do material que deu origem a algumas das reflexões aqui apresentadas. 
Nos últimos anos, as indenizações vêm se tornando políticas de reparação, de justiça social e de direitos humanos cada vez mais frequentes. Embora o universo das indenizações seja vasto e ultrapasse o campo dos direitos sociais - a exemplo das companhias públicas e privadas que negociam seguros de vida, de saúde, de bens móveis e imóveis - é a partir dele que se estabeleceram as práticas, as justificativas e os parâmetros que interessam para a discussão proposta. No Brasil, as indenizações foram associadas aos primeiros projetos hidroelétricos implementados, como as usinas de Moxotó e Sobradinho, construídas no rio São Francisco, na região Nordeste do país. Contudo, embora tais projetos tenham sido iniciados respectivamente em 1971 e 1973, apenas dez anos depois as populações tiveram atendidas as reivindicações de reassentamento, indenização, assistência técnica, entre outras, o que ocorreu apenas com a interferência do Banco Internacional para a Reconstrução e o Desenvolvimento (Vianna Júnior 2018). Ainda assim, mobilizações de trabalhadores rurais, indígenas e ribeirinhos, até o final da década de 80 , seguiram exigindo indenizações justas e demais medidas reparatórias, denunciando a falta de compensação por perdas culturais, econômicas, sociais e ambientais resultantes do deslocamento compulsório (Vianna Júnior 2018: 24).

No final dos anos 80, no Brasil, a abertura democrática estimulou a organização social e política de coletivos emergentes ou que haviam sido postos em clandestinidade. Nesse contexto, foi realizado em 1989 o I Encontro Nacional dos Trabalhadores Atingidos por Barragens, sendo esse o primeiro encontro em que pessoas reunidas sob a categoria "trabalhadores" construíram uma agenda crítica aos grandes projetos de barramento de rios em diferentes regiões do país. O documento final desse encontro apresenta o tema das indenizações de maneira mais ou menos explícita sob a forma de "cumprimento dos acordos" enquanto medidas urgentes a serem efetivadas (Vianna Júnior 2018: 32). De acordo com Ferreira e Marques (2008), nesse período inicial da estruturação do que viria a ser o Movimento Nacional dos Atingidos por Barragens (MAB), havia a preocupação de algumas de suas lideranças de que o envolvimento com pautas mais amplas resultasse na perda do foco nas questões mais específicas dos atingidos, que eram, precisamente, as indenizações e os reassentamentos (Ferreira e Marques 2008: 236).

Como efeito de tais debates públicos, em projetos de desenvolvimento como Belo Monte, as indenizações são práticas previstas desde o início do planejamento do empreendimento. No entanto, a essa altura, a abrangência e os critérios de mensuração de valor não estão definidos. No contrato de concessão firmado entre o Ministério de Minas e Energia (MME) e a empresa Norte Energia, em 2010, foi prevista como prerrogativa da concessionária "a promoção de forma amigável, [d]a liberação das áreas de terra necessárias à 
operação da UHE $[\ldots]$ cabendo [...] as providências necessárias para sua efetivação e o pagamento de indenizações" (Contrato de Concessão n. ${ }^{\circ}$ 01/2010-MME-Norte Energia: 14). ${ }^{3}$ Trata-se, como vemos, da aquisição de terrenos que seriam necessários para a operação da UHE Belo Monte.

Posteriormente, foram incluídas como parte dos investimentos obrigatórios a serem realizados pela empresa as ações de "requalificação urbana", entre as quais consta o "reassentamento" de cerca de 4362 famílias moradoras de "áreas impróprias", "de risco ('sujeitas a enchentes')" ou "irregulares do ponto de vista legal (ocupação em APP)" (Norte Energia 201 1: 40). É interessante observar que nesse documento da empresa, como também em vários outros, as características das moradias recebem mais destaque do que a informação fundamental de que o reassentamento se justifica "por força da formação do reservatório da UHE Belo Monte (id. ibid.). Ou seja, as áreas de beiras de rio e igarapés - então referidas como áreas de moradias precárias, perigosas e ilegais seriam alagadas devido à própria barragem.

Moradores das margens do rio Xingu - o que correspondeu a cerca de 25\% da área urbana da cidade - tiveram suas casas marcadas, medidas, classificadas e fotografadas, sem que lhes fossem fornecidas as informações que ansiavam receber: Seriam removidos dali? Para onde iriam? Quando? Estavam correndo perigo de vida ao permanecerem, uma vez que as obras da barragem já haviam começado? Junto com a marcação de suas casas, os funcionários informavam que após o "registro" das condições da propriedade quaisquer eventuais benfeitorias não seriam contabilizadas para fins de indenização. Além das benfeitorias, não seriam considerados novos moradores nas casas cadastradas, nem novas casas nos bairros já visitados. Esse marco temporal, imposto pela empresa, foi nomeado de "congelamento".

Os critérios de classificação utilizados pela Norte Energia foram complexos, quase sempre exógenos aos moradores e seguem desconhecidos por estes. Além da área do terreno (em metros quadrados), os outros critérios foram: localização (periferia/centro), vocação (residencial/comercial), risco de alagamento (forte, médio ou nulo), registro (matrícula ou contrato de compra e venda), infraestrutura da via pública onde está localizado o imóvel (nula, pouca, muita ou completa), edificação (presente/ausente) (Norte Energia 2013: 8). Um aspecto dos imóveis que recebe destaque ao longo de todo o Projeto Básico Ambiental é a estrutura de palafita, categoria que não faz parte da linguagem local. Os documentos da Norte Energia consultados são recheados de imagens de passarelas e casas de madeiras suspensas sobre águas. Em nenhum desses documentos constam fotografias de casas de madeira em terra firme, o

3 Contrato de Concessão N. ${ }^{\circ}$ 01/2010-MME-UHE BELO MONTE. De uso de bem público para geração de energia elétrica, que celebram a união e a empresa Norte Energia SA. Processo N. ${ }^{\circ} 48500.003805 / 2010-81$. 
que permitiria observar que a estrutura de madeira representa um padrão de moradias na cidade e na Amazônia de maneira geral, não sendo sinônimo de palafitas. Nos documentos da empresa as referências às palafitas aparecem, amiúde, associadas à precariedade e vulnerabilidade, a ver: "área com ocorrência de palafita" (2013: 31), "estruturas de palafitas onde vivem milhares de pessoas com alto grau de vulnerabilidade" (2013: 31), "forma de ocupação precária, ou seja, palafitas" (2013: 33), "habitações subnormais construídas sobre palafitas, habitadas por população de baixa renda" (2013: 35). Apesar de tais afirmações, o tipo de material empregado na construção das casas não foi utilizado pela empresa como um critério de definição das indenizações.

Maria Lacídia e Chiquinho, hoje moradores do RUC Jatobá, viviam na rua da Peixaria, uma área próxima da beira do igarapé Ambé. O casal vivia em uma casa "de tábua" ou "de madeira", como se referiam. Moradias desse tipo têm a vantagem de serem mais econômicas, mais frescas, de mais rápida construção e, se bem construídas, mais resistentes às enchentes, pois são menos aderentes à umidade. Por outro lado, as casas de madeira são mais vulneráveis à violência urbana e mais suscetíveis à entrada de bichos, além de necessitarem mais frequentemente de manutenção. Durante os trabalhos dos funcionários da Norte Energia, a moradia do casal foi referida como "palafita", o que foi compreendido por Maria como "parasita", o que lhe pareceu extremamente ofensivo. No decorrer das práticas de classificação dos imóveis em Altamira, a população que vivia nas beiras de rio e igarapés, mais do que qualquer outra da cidade, foi confrontada com sua própria precariedade. A vulnerabilidade produzia-se na interação entre funcionários da empresa e moradores de áreas consideradas precárias, tornando impossível qualquer tentativa de negociação individual, fosse visando ampliar o valor da indenização, fosse visando incorporar outras dimensões aos termos da classificação.

O casal não soube dizer como a casa em que viviam foi avaliada segundo os critérios vigentes, mas foram comunicados de que receberiam uma casa em um dos reassentamentos com direito a um ponto comercial para instalação do estúdio de tatuagem de Chiquinho. Embora, no âmbito do projeto de desenvolvimento de Belo Monte, as práticas de indenização tenham sido de três tipos (pagamento em dinheiro, carta de crédito imobiliário e reassentamento), as moradoras e os moradores de áreas consideradas precárias não tiveram escolha a não ser o reassentamento. Com o passar do tempo (foram cerca de 30 meses), Maria Lacídia e Chiquinho animaram-se com a perspectiva de viver em um dos reassentamentos que, segundo diziam os técnicos e a propaganda da empresa, seria urbanizado (não sujeito a alagamentos) e não ficaria a mais de dois quilômetros de onde viviam, e disporiam de escolas, posto de saúde e fácil acesso ao transporte.

Dona Rosa Pessoa, moradora de uma avenida bastante movimentada e próxima ao centro, também não conheceu os critérios que foram utilizados 
para avaliar seu terreno, uma área de aproximadamente $300 \mathrm{~m}^{2}$ nos fundos de sua casa, onde tinha plantas e árvores frutíferas cultivadas durante os quase 20 anos de vida na propriedade. Para ela, mais importante do que as árvores, flores e plantas, era o que seu quintal representava. Na parte mais distante do seu terreno, havia uma entrada para o igarapé onde ela se refrescava, relaxava, organizava confraternizações com seus familiares e também encontrava refúgio nos dias de tristeza pelo filho que ainda jovem fora assassinado. ${ }^{4} \mathrm{~A}$ parte do terreno que lhe foi tirada, assim, estava diretamente relacionada às suas memórias. Por esses e outros motivos, dona Rosa não quis vender seu terreno e indignava-se com o que considerou uma "maneira muito estranha de negociar", que é "querer comprar o que não está à venda" e, ainda por cima, "botando preço".

Ao perder uma parte de seu terreno, dona Rosa perdeu plantas, árvores, bichos. Perdeu o acesso ao igarapé, perdeu o lugar de suas memórias. Algum tempo depois, perdeu ainda outras plantas e outras árvores, pois foi necessário aterrar toda a área de terreno que lhe sobrou para evitar possíveis alagamentos em função das obras públicas que elevaram o nível da rua nas imediações de sua casa. A indenização, assim, foi tristemente consumida por três caminhões de aterro. O dinheiro que recebeu por algo que não estava à venda foi "empatado" para corrigir um problema criado, também, pela construção de Belo Monte. Ter de vender algo que não estava à venda produziu em dona Rosa a sensação de que não era mais ela quem tomava as decisões em sua vida, ela "apenas se adaptava". Voltaremos a esse ponto adiante.

No RUC Jatobá, a casa que Maria Lacídia e Chiquinho receberam foi construída com placas de concreto e não de alvenaria, como havia sido anunciado. Eles receberam uma casa, como todas as outras, de $63 \mathrm{~m}^{2}$, composta por três quartos, sendo uma suíte, cozinha americana, piso de cerâmica, pequena varanda frontal, quintal e tanque de lavar roupas na área externa, sem cobertura. Além de receberem uma casa de qualidade inferior à informada, também não houve as três opções de tamanho anunciadas. Além disso, foram reassentados a seis quilômetros da antiga morada, sem qualquer um dos serviços prometidos. As placas de concreto utilizadas na construção permitiram ao empreendedor maior agilidade na obra e menor custo, mas resultou em dois problemas para os moradores: casas quentes e sem possibilidade de instalação de fixadores de rede, item central no modo de vida da população local. Em pouco tempo, começaram as infiltrações, rachaduras e refluxo do esgoto.

Contudo, o que pareceu pior para Maria Lacídia e Chiquinho é que não receberiam o ponto comercial que lhes havia sido prometido para instalação do estúdio de tatuagem. Segundo Chiquinho, foi só depois de vários meses

4 Jaenes da Silva Pessoa tinha 13 anos quando foi assassinado em Altamira, em 1992, em meio a um conjunto de crimes conhecidos como de "emasculação". Para maiores informações, conferir Lacerda (2014). 
vivendo no reassentamento - e exigindo o que lhes havia sido prometido - que os funcionários da Norte Energia disseram que o comércio dele era "pequeno", cabendo a ele próprio construir em área anexa ao seu terreno, caso quisesse, mediante compra da área junto à empresa. De fato, foi o que Chiquinho fez, mas não sem antes precisar entrar na justiça para poder comprar o terreno que, por motivo contratual, não poderia ser objeto de compra e venda antes de cinco anos a contar da data de entrega das casas.

É possível que Chiquinho não tenha recebido um ponto para instalar seu estúdio de tatuagem porque sua propriedade foi classificada como residencial. Os critérios da Norte Energia, acima descritos, explicitam quais categorias são trabalhadas de "forma dicotômica", isto é, que contemplam apenas uma das duas opções descritas, e a "vocação do imóvel” é uma delas. Isso significa que as residências com comércio contíguo podem ter sido classificadas simplesmente como "residência". Para Chiquinho, o alvará de funcionamento da prefeitura, a autorização de funcionamento da vigilância sanitária e outros documentos oficiais comprovavam a existência e a legalidade do ponto comercial do qual tirava seu sustento. Para os funcionários da Norte Energia, não.

Para Maria Lacídia, a promessa da empresa de que teriam um ponto comercial separado da sua residência fez com que ela passasse a ter o "sonho" de viver no reassentamento. A notícia de que ela e seu marido não teriam o ponto comercial foi recebida com decepção pelo casal ("eles prometeram"). Junto a isso, eles descobriram ainda que, para os funcionários da Norte Energia, o estúdio de tatuagem de Chiquinho era "pequeno", não sendo adequado para figurar entre os comércios do reassentamento. Nesse processo, a renda do casal foi bastante reduzida, pois além de perderem o estúdio de tatuagem, perderam a freguesia dos cosméticos e dos tapetes artesanais que Maria Lacídia vendia em sua casa, que foram considerados "trabalhos domésticos". Em depoimento registrado por Carlos Fausto e Thiago Oliveira, Maria Lacídia revela que além dos efeitos financeiros, enfrentaram algo pior: a destruição de um sonho.

“Se eles tivessem dito 'não, vocês não vão ganhar', desde o início... mas eles prometeram. 'Quem tem comércio na frente da sua residência, vai ter uma casa e um ponto. [...] Na sua mente, você faz um projeto, vou ganhar a minha casa, vou fazer o meu comércio, vai ser assim, assim, assim. Quando eles mostraram a casa, eles mostraram a casa e o ponto, né? Até aí foi maravilhoso. Aí quando eu pedi pra ele comprar o material porque no inverno as coisas se tornam mais em conta, ele foi encostar os tijolos, aí pronto. Falaram que tava vendido pros empresários maiores porque ele era pequeno. Falaram que não era nem comércio porque era estúdio de tatuagem. Até nisso - eu falei pra eles - vocês tiraram meu sonho. Porque eu já tinha uma casa [em] que o comércio era em frente à minha sala, então pra pessoa passar pra minha sala, tinha que passar pelo comércio. Então o sonho 
que vocês realizaram e depois mataram, isso faz qualquer uma pessoa ficar doente mental. Porque você faz o plano na sua mente." [Entrevista com Maria Lacídia, março de 2016]

\section{OS CONTORNOS DA ESPERA}

Entre o início das visitas dos técnicos às residências - para medir, fotografar, marcar - e a efetivação das medidas de indenização passaram-se longos períodos, que variaram de dois até cinco anos. Em todos os casos analisados, o tempo entre um momento e outro não foi menor do que dois anos e meio. Isso significa não só que durante esse período foi incerto o destino dos moradores de Altamira, como também que eles estiveram envolvidos em situações tensas e desconfortáveis quanto a aspectos cotidianos e estruturantes da vida, como a qualidade da casa em que residiam, como e com quem moravam, o tipo de trabalho que exerciam. Para compreender os aspectos tensos e desconfortáveis dessas situações é preciso ter em mente que os moradores não só consideravam possuir informações insuficientes sobre os projetos que afetariam suas vidas, como também se sentiam em condição desvantajosa em relação aos funcionários que, diante deles, representavam “o empreendimento". Aqui, os mecanismos de governo compreendidos no sentido empregado por Foucault (2014) podem ser compreendidos a partir de três conjuntos de estratégias que caminharam juntas, em desfavor dos moradores: a produção da ilegibilidade (Das e Poole 2004), a produção da indiferença (Herzfeld 2016) e a gestão da desigualdade (Souza Lima 2002). Tais práticas tiveram a administração do tempo como um instrumento operador de suas dinâmicas e se respaldaram em linguagens e procedimentos incompreensíveis.

No caso de Dona Rosa, como vimos acima, foram mais de cinco anos aguardando alguma definição que lhe permitiria tomar decisões. Em 2010, Dona Rosa foi informada que seria indenizada, pois o volume do igarapé Altamira alcançaria sua casa. Ao mesmo tempo em que ficou triste e angustiada, porque sua casa representava muito para si e porque não sabia para onde ir, Dona Rosa ficou surpresa e desconfiada. Se as águas do igarapé Altamira realmente alcançassem sua casa, uma área muito extensa seria afetada, inclusive de empresas nas imediações. Será que todos aqueles imóveis seriam removidos dali ou dizer que sua casa seria alagada era apenas uma estratégia para fazê-la sair? Ou acelerar sua saída? Mesmo assim, Dona Rosa fez planos. Pensava em morar com seu marido no sítio, localizado na parte rural de Altamira. Pensava em comprar uma chácara na periferia de Belém, capital do estado, onde poderia ficar mais perto de uma das filhas. Pensava em permanecer na casa. E ao mesmo tempo buscava terrenos em outras partes de Altamira onde pudesse construir. Um ano após o outro se passava sem que Dona Rosa tivesse certeza do que fazer. Nenhuma proposta, nenhum valor, nenhuma definição acerca dessa dimensão 
tão central da vida que é o morar. As incertezas fizeram com que Dona Rosa considerasse que mesmo "depois de velha" perdera a "autonomia de sua vida".

O sociólogo argentino Javier Auyero, em sua obra Pacientes del Estado, analisa a espera como uma forma de dominação cotidiana que se impõe sobre os pobres, especialmente sobre aquelas (trata-se, majoritariamente, de mulheres) que acessam serviços públicos. Para o autor, a incerteza, a arbitrariedade, a confusão e o mal-entendido são estratégias eficazes de transformação de cidadãos de direitos em "pacientes do Estado" (Auyero 2013: 66). Para o autor, não é por decisão de alguém que as pessoas são submetidas a longas filas e longas esperas. Isso ocorre devido a uma estrutura que não só torna tais práticas possíveis como previstas. Por meio delas, segundo o autor, ensina-se algo aos que esperam: a esperar, bem como os modos adequados de fazê-lo. Em meio a tal processo, a espera converte-se em indicador de perseverança e de necessidade real (Auyero 2013: 68). Assim, suportar horas de fila nas dependências públicas ou esperar anos por uma indenização tornam-se práticas cujos efeitos incidem diretamente sobre a avaliação que se faz desses sujeitos que esperam. No nosso caso, podemos dizer que ao mesmo tempo em que a espera converte moradores em bons cidadãos (pacientes, ordeiros e determinados), os produz enquanto sujeitos inferiores, cuja sorte é poder esperar por melhorias, ainda que estas sejam moradias de má qualidade ou indenizações insuficientes.

O caso de Claudia, ex-moradora de um bairro inteiramente removido, nos permite compreender a espera como um mecanismo ativo de produção de ilegibilidade, indiferença e desigualdade, mas também o direcionamento do tempo de forma mais ampla, a própria possibilidade de ditar os tempos, seja de espera, seja de urgência. Nesse caso, veremos que enunciados informais e pouco claros têm efeitos de provocar tomadas rápidas de decisão, o que se deve à combinação entre o acionamento de incertezas e de certos perigos. Claudia possuía um comércio de revenda e roupas finas, que ela mesma produzia para casamentos, batizados e festas de quinze anos, na entrada de sua casa, com alvará de funcionamento expedido pela autoridade municipal. Sabendo que algumas pessoas que possuíam comércio tinham sido indenizadas, além de receberem a casa em um dos RUC, Claudia queria garantir o mesmo direito. Contudo, via suas chances de receber a indenização diminuídas a cada vizinho que se mudava para um dos reassentamentos. Com o esvaziamento do bairro, a clientela também minguou. Claudia persistia na antiga morada, exigindo sua indenização antes da mudança. Acreditava que a partir do momento em que aceitasse a casa, o "fato estaria consumado" e ela não disporia de quaisquer canais para seguir exigindo a indenização.

A espera que Claudia administrava com angústia, mas também como estratégia, foi interrompida após visita de um dos funcionários da Norte Energia. Diante da condição de só deixar a casa após ser indenizada pelo seu comércio, o funcionário encerrou a conversa dizendo a Claudia que ela "ia ficar pra trás, 
sozinha no baixão junto com as carapanãs [mosquitos]". Com essa única frase, o funcionário produz uma série de enunciados, com efeitos de verdade, sobre a vida de Claudia, os quais ela compreendeu prontamente. Primeiro, ao dizer que Claudia morava num "baixão", afirma-se que ela vivia em área desassistida, desvalorizada e perigosa. Segundo, ao dizer que ela "ficaria pra trás", o funcionário comunica que o pleito de Claudia não seria alcançado, não adiantando o quanto esperasse. Por fim, "ficar pra trás, sozinha no baixão junto com as carapanãs" pode ainda querer dizer sobre os perigos que Claudia, uma mulher solteira, desafiava ao permanecer na residência em busca do que considerava como seu direito. Aqui, a fronteira entre o alerta e a ameaça é manejada em desfavor de Claudia, se não com intenção, ao menos como possibilidade viabilizada pela situação de assimetria de poder, de gênero e de classe que separava a moradora do funcionário.

Os estudos sobre a chamada "burocracia do nível do chão" (street level bureaucracy), termo proposto por Lipsky (1980), apresentam aportes importantes para compreendermos a centralidade da interação entre cidadãos e burocratas na avaliação que os primeiros fazem sobre os serviços públicos prestados. $\mathrm{O}$ atendimento considerado ineficiente, displicente ou desatencioso tem mais efeito sobre as avaliações de legitimidade e de confiabilidade do que elementos como o fundamento, o método e a abrangência que estruturam as políticas. Zacka (2017), realizando uma abordagem mais recente em torno do conceito proposto por Lipsky, afirma que "como alguém é tratado é tão crucial quanto o que recebe" (Zacka 2017: 9). Para esse autor, a implementação adequada de serviços públicos depende da capacidade de atuação dos burocratas enquanto agentes morais sensíveis que possam, entre outras coisas, interpretar diretivas vagas e utilizar estrategicamente recursos quase sempre escassos (Zacka 2017: 6). Nesse sentido, a queixa dos moradores de Altamira a respeito da forma como foram percebidos e tratados por funcionários do empreendimento, mais do que relativa a sujeitos particulares, aponta para dimensões mais amplas em torno da experiência em processos políticos calcados na desigualdade e na assimetria, conforme passaremos a discutir.

\section{A assimetria que produz a dádiva}

As análises do tema do desenvolvimento, principalmente no campo das ciências sociais, confluem na crítica à maneira pouco plural com que a ideia de desenvolvimento é operada por meio dos projetos, quase sempre desacompanhada de qualquer definição, como se desenvolvimento fosse princípio evidente e de sentido único, além de seguramente positivo (Escobar 1995; Ferguson 1996; Ribeiro 2008; Bronz 2011). Buscando oferecer uma contribuição crítica ao conceito, Ribeiro defende que o desenvolvimento seja compreendido como uma ideologia sustentada por um campo de poder que busca a hegemonia e, para tanto, afirma-se como um modelo com soluções para os mais graves 
problemas dos países "em desenvolvimento", como a pobreza e a desigualdade. Contudo, esses problemas são justamente os que garantem a plasticidade do discurso do desenvolvimento, sempre em vias de solucionar problemas, em processo de cumprir promessas etc. (Ribeiro 2008: 1 17). Assim, a relação entre desigualdade e desenvolvimento não é de anterioridade de uma sobre a outra, mas de mútuo fortalecimento, crescimento e amadurecimento. Através da concretude de projetos como os que analisamos aqui, desigualdade e desenvolvimento tornam-se categorias indissociáveis, partes fundamentais dos discursos em defesa dos projetos, que afirmarão que o desenvolvimento é um caminho para a superação das desigualdades (Ferguson 1996; Bronz 2011).

Como vimos no caso da UHE Belo Monte, o atraso, a precariedade e o subdesenvolvimento de vidas, casas e territórios, tornam-se matéria fundamental na estruturação das propostas, no estabelecimento de práticas e nas percepções mutuamente construídas, ainda que em situações de desigualdade de poder. As assimetrias às quais faço referência demarcam as posições desiguais entre moradores de Altamira e funcionários da empresa responsável pela obra de construção da hidroelétrica. Ao reconstituir com meus interlocutores as experiências de contato com os funcionários, fosse no momento de marcação e medição das suas casas, fosse posteriormente, quando alguns já habitavam os reassentamentos, observei o uso reiterado de fórmulas específicas para se referir a eles. Os interlocutores e, em especial, as interlocutoras se referem aos funcionários como homens ("os funcionários", "os empregados"), pessoas de fora ("desconhecido", "nunca tinha visto na vida", "não conhece Altamira") e escolarizados e/ou bem remunerados ("veio com um aparelho eletrônico para medir", "falou coisas que eu não entendi", "pegam avião [para ir embora?] todo fim de semana"). Tais percepções são eloquentes em comunicar distâncias e assimetrias, pois sugerem que os "funcionários" sejam gente mais "importante" e "de fora", em quem não se pode confiar e sequer poderia ser encontrada em um futuro próximo.

$\mathrm{Na}$ verdade, o que está sendo tratado aqui como funcionários da empresa responsável pela construção da hidroelétrica, ou funcionários da Norte Energia, são variações das classificações empregadas em Altamira. A construção de Belo Monte funcionou em regime consorciado, o que quer dizer que não uma, mas um conjunto de empresas foi responsável pelo empreendimento. Contudo, como foi sinalizado anteriormente, são empresas e fundos públicos que detêm a quase totalidade do capital da Norte Energia. ${ }^{5}$ A Norte Energia, por sua vez, formou o Consórcio Construtor de Belo Monte (CCBM), formado por

5 A lista completa das empresas que compõem a Norte Energia é a seguinte: Eletrobrás, Chesf, Eletronorte (com 49,98\% do capital), entidades de previdência complementar como Petros e Funcef (20\%), Vale, Cemig e Sinobrás (10\%), Belo Monte participações (10\%), Light e Cemig (9,77\%) e J. Malucelli Energia (0,25\%). 
grandes empresas - algumas formadas por conglomerados - de capital fechado, porém com longa trajetória em grandes obras públicas. Entre essas empresas, temos: Andrade Gutierrez, Camargo Corrêa, Odebrecht, Queiroz Galvão, OAS, Contern, Galvão, Serveng, J. Malucelli e Cetenco. O Consórcio Construtor de Belo Monte contratou empresas terceirizadas para a realização dos serviços constantes no Projeto Básico Ambiental. É com esse último conjunto de empresas que as moradoras e os moradores interagiram durante o processo de remoção, indenização e reassentamento que se estende até os dias atuais.

O formato consórcio - que nos remete à imagem de uma boneca russa, em cujo interior existem outras bonecas e assim sucessivamente - foi definido por Ribeiro (2008) como "blocos de construção que [...] transformam-se em novas instituições, as quais podem virar as unidades de novos e mais complexos consórcios" (Ribeiro 2008: 115). Para esse autor, o formato "consórcio" nos projetos de desenvolvimento é resultado de um processo político em que ressalta o comando por parte de grupos de poderes que atuam de forma bastante integrada. Um dos efeitos desse formato de negócio para moradores de Altamira consiste justamente na dificuldade em lidar com o "empreendedor". Em pesquisa sobre a atuação do Ministério Público Federal no caso de Belo Monte, Vilaça (2017) apresenta a fala de uma procuradora que descreve o contexto das supostas negociações entre moradores e representantes do empreendimento.

"Pessoas analfabetas, humildes, negociando em uma mesa com a empresa sozinhas, completamente sozinhas. E se a pessoa não concordar [...] o que a empresa faz, a empresa tem o advogado que vai explicar pra ela as regras do processo. Aí vem o advogado e explica porque tinha que ser daquele jeito, que ela tem que concordar. Então não tem negociação nenhuma, porque você tem que aceitar o que eu estou te impondo. [...] Então quando eu vi isso, eu tive a nítida percepção de que a Norte Energia estava fazendo o papel dela, a Norte Energia é o empreendedor" (Vilaça 2017: 94)

O desdobramento da atuação do Ministério Público nesse tema, como narra a promotora na sequência de sua fala, foi a pressão para que a Defensoria Pública da União assumisse a tarefa de acompanhar as negociações relativas aos reassentamentos e às indenizações. Um aspecto relevante no tema da interação entre moradores e representantes do empreendimento é que a expertise de luta e de reivindicação de moradores de Altamira perante lideranças do governo, especialmente devido a experiências prévias de participação em movimentos sociais da região, não só se revelou inútil diante das dinâmicas e da estrutura da Norte Energia e suas subdivisões, como produziu estranhamentos e incertezas que acentuaram as assimetrias e as desigualdades entre eles e os representantes do empreendimento. Assim, é possível afirmar que diferente 
de lidar com o Estado, que apesar de sua dimensão abstrata (Abrams 1988) possui representantes conhecidos, mesmo que inalcançáveis, o empreendedor é desconhecido, sequer se sabe se mora no Brasil, pode até mesmo não ser brasileiro. A intangibilidade que essa figura assume, paradoxalmente, produz a materialização de cada um dos funcionários desconhecidos que trabalham para a Norte Energia na figura do empreendedor, embora claramente se saiba que nenhum deles o seja.

Nas situações de interação entre moradores e funcionários da empresa, as assimetrias estruturais tornam-se visíveis e demonstram a capacidade de alterar os significados do que é o bem morar, do que é direito e do que é a indenização. Assim, a obrigatoriedade das indenizações e os parâmetros que as regulamentam parecem estar menos sujeitos a normas e contratos firmados registrados e fiscalizados em/por órgãos do governo e mais sujeitos a interpretações, aplicações particulares, parciais e instáveis por parte daqueles que as manejaram na prática. No contexto das relações permeadas por impressões sobre precariedades, carência e insuficiência, a indenização devida torna-se tema deslizante em que assume as feições de uma dádiva. Com isso, as indenizações passam a ser operacionalizadas como um presente inesperado, como uma inequívoca melhoria de vida a custo zero, cabendo aos moradores aceitá-la, com satisfação e gratidão.

A dimensão de dádiva que as indenizações assumem torna-se ainda mais evidente diante de situações de assimetria de gênero. Acima, vimos como a saída de Claudia de sua antiga moradia esteve atravessada pela manipulação do tempo, do medo e da ameaça, dimensões que alcançam robustez pelo fato de ela ser mulher. Para demonstrar esse aspecto com maior ênfase, encerro esse tópico com a análise de situações vividas por Edizângela, uma mulher negra de cerca de 35 anos, mãe de cinco filhos e líder do Movimento dos Atingidos por Barragens (MAB). No relato que transcrevo abaixo, as dimensões de repressão, pressão e humilhação constituem os processos que analiso como sendo de transformação do direito à indenização em dádiva. Em suas palavras:

“Eles estavam lá - o grupo da Norte Energia - negociando. [...] Então, a gente tentou fazer uma manifestação dizendo que a gente não queria a barragem porque a gente já sabia que [...] o peixe ia morrer, que o rio ia se acabar, que as árvores iam se acabar, tudo isso. E aí eles ficaram muito apavorados, estava cheio de engenheiros da Norte Energia, e um dos engenheiros, um cara chamado Edson, chegou no meu ouvido e disse assim: 'olha, eu vou the dar uma casa para você e pra sua comunidade em cima do lixão e ela vai ser de concreto', e eu nem sabia o que era concreto. Ele fez isso e eu fiquei sem palavras, porque ele falou no meu ouvido, bem no meu ouvido, fiquei sem reação. [...] O que o cara falou para mim, muitos anos depois, depois de quatro anos da barragem construída, foi o que eles fizeram 
em vários assentamentos. Um dos assentamentos é o Casa Nova e o São Joaquim, que são construídos de frente para o lixão, o Casa Nova fica bem na parte de trás do aterro sanitário. O Casa Nova fica de um lado e o São Joaquim fica do outro. E as nossas casas foram feitas de placas de concreto como ele falou que ia fazer. Então, ele já tinha falado isso para mim como uma forma de pressão. E humilhação também.

$\mathrm{Na}$ audiência pública [...] o chefe geral da Norte Energia chegou para mim e disse que 'queria ouvir um elogio', porque a gente sempre reclama deles e nunca diz um elogio para eles. Eu respondi para eles 'elogio porquê, se tudo que a gente tem foi conquistado na nossa luta?'. Não foi dado por eles. É isso, a gente nunca tem nada dado pela empresa e o cara queria um elogio. Ele disse assim: 'é isso mesmo, tem que lutar'. E eu disse: 'então, se você sabe que a gente tem que lutar, por que você quer um elogio?'. Não merece um elogio. Pra mim, isso também foi uma forma de repressão. Ele quis me diminuir naquele momento. Nesse processo todo, a gente tem que aprender a lutar pelos nossos direitos, por uma vida melhor como eles dizem que a gente tem que ter, e, ao mesmo tempo, aprender a lidar com o empreendedor, porque se a gente não aprender a lidar com eles, é muito difícil." [Entrevista com Edizângela Barros, novembro de 2016]

As situações narradas por Edizângela são fortes pelo que evidenciam e pelo que permitem descortinar acerca do universo em que funcionários homens estiveram em posição de medir, avaliar, classificar moradias de mulheres e estipular indenizações para elas. Nesses casos, a indenização converte-se não só em uma dádiva, mas em uma dádiva masculina. Na primeira situação, através de um contato físico incomum, imprevisto e inadequado ("ele chegou no meu ouvido"), um dos engenheiros da empresa responsável pelo empreendimento diz coisas ameaçadoras - principalmente porque não foram, àquela altura, compreendidas - sob o formato de uma figura masculina provedora e fictícia ("eu vou lhe dar uma casa"). Na segunda situação, através de uma frase ("[ele disse que] queria ouvir um elogio") em meio a uma cena de aproximação falsamente amistosa, outro representante da empresa pretende transformar direitos em favores, voluntarismo e, por isso, demanda reconhecimento e gratidão.

\section{PERSPECTIVAS FINAIS}

Ao recuperar alguns contextos em que funcionários da empresa responsável pela construção de Belo Monte e moradores de Altamira estiveram envolvidos, meu objetivo foi descrever e analisar a estruturação da assimetria e sua ativação através de situações em que um projeto de desenvolvimento enseja modos específicos de governo e gestão das desigualdades. Assim, os atos de classificação e precificação sobre o que não estava à venda, o controle sobre o 
cotidiano através da administração do tempo e a produção dinâmica de assimetrias, foram as práticas que escolhi descrever e analisar visando demonstrar quais foram os efeitos, em Altamira, de processos políticos movidos por ações de indenizações no âmbito de um grande projeto considerado de desenvolvimento.

Ao longo dessas páginas, procurei compreender as reflexões, os cálculos e as práticas dos moradores de Altamira, meus interlocutores, diante de situações assimétricas e adversas que experienciaram, o que eu gostaria que fosse compreendido como parte de um processo político durável e complexo. Nesse sentido, argumentei que a implantação da UHE Belo Monte produziu transformações sobre dimensões centrais na vida das pessoas, como o morar e o deslocar-se pela cidade. Com isso, foram desconstruídas e reconstruídas redes de sociabilidade e novas formas de ganhar a vida, pois o morar implica em fazer vizinhança, clientela, amizades, cercar-se de uma rede segura que possa auxiliar em atividades cotidianas como o olhar as crianças, o emprestar um alimento, vigiar a casa. Nesse sentido, as transformações são também do âmbito da subjetividade, pois se expressam na construção de novos desejos, novas expectativas, na adesão a novos projetos de vida. Essas transformações subjetivas em face a processos políticos mais amplos correspondem ao que Foucault (2014) definiu como sendo a encarnação da verdade e da racionalidade nos sujeitos através de formas de governo, como busquei demonstrar.

Ao lado das análises que apontavam para aspectos técnicos e políticos como o descompasso entre o montante (vultuoso) de investimentos que eram aplicados nesse projeto e os resultados energéticos que dele se poderiam depreender, ao lado da resistência sistemática e corajosa de uma parte organizada da população de Altamira, estiveram alguns de meus interlocutores que, se não desde o início, a partir de um dado momento, passaram a desejar as mudanças prometidas, acreditaram nos planos apresentados, sonharam com a casa nova, com o bairro novo, com a cidade nova e moderna. Essas expectativas não estão dissociadas do histórico da região fundada e refundada através de projetos de desenvolvimento. Vencer a selva com a estrada, vencer os indígenas com colonos, vencer o rio com a barragem, vencer as palafitas com tijolos, são narrativas épicas sobre a vitória do desenvolvimento e da civilização sobre o local, o habitual, o costumeiro, algo que, através das políticas e das práticas de indenização aplicadas nos últimos anos em Altamira, foi mais uma vez atualizado. 


\section{BIBLIOGRAFIA}

ABRAMS, Phillip, 1988, "Notes on the difficulty of studying the state", Journal of Historical Sociology, 1 (1): 58-89.

ALMEIDA, Alfredo Berno de, e Rosa Elizabeth MARIN, 2014, "Pescadores, ribeirinhos e indígenas: mobilizações étnicas na região do rio Xingu: resolução não negociada de conflitos na Usina Hidroelétrica de Belo Monte", in João Pacheco de Oliveira e Clarice Cohn (orgs.), Belo Monte e a Questão Indígena. Brasília, DF: ABA, 143-169.

AUYero, Javier, 2013, Pacientes del Estado. Buenos Aires: Eudeba.

BRONZ, Deborah, 2011 1, Empreendimentos e Empreendedores: Formas de Gestão, Classificações e Conflitos a Partir do Licenciamento Ambiental, Brasil, Século XXI. Rio de Janeiro: Universidade Federal do Rio de Janeiro, tese de doutorado apresentada ao programa de pós-graduação em Antropologia Social.

CERQUeIRA, Daniel, Renato Sergio BUEnO, Luis Iván VAlEnCIA, Olaya HANASHIRO, Pedro Henrique MACHADO, e Adriana dos Santos LIMA., 2017, Atlas da Violência 2017. Brasília, DF: IPEA, Fórum Brasileiro de Segurança Pública.

COHN, Clarice, 2010, "Belo Monte e processos de licenciamento ambiental: as percepções e as atuações dos xikrin e dos seus antropólogos", Revista de Antropologia Social dos Alunos do PPGAS-UFSCar, 2 (2): 224-251.

DAS, Veena, e Deborah POOLE, 2004, "State in its margins: comparative ethnographies", in Veena Das e Deborah Poole (orgs.), Anthropology in the Margins of the State. Santa Fé: School of American Research Press, 3-34.

DOMingues, William César Lopes, 2017, Cachaça, Concreto e Sangue! Saúde, Alcoolismo e Violência. Povos Indígenas no Contexto da Hidroelétrica de Belo Monte. Belém: Universidade Federal do Pará, dissertação de mestrado apresentada ao programa de pós-graduação em Antropologia.

ESCOBAR, Arturo, 1995, Encountering Development. The Making and Unmaking of the Third World. Princeton, NJ: Princeton University Press.

FERGUSON, James, 1996, "Development", in Alan Barnard e Jonathan Spencer (orgs.), Encyclopaedia of Social and Cultural Anthropology. Londres: Routledge, 189-196.

FERREIRA, José Ivaldo, e Juracy MARQUES, 2008, "A invenção dos royalties: a conquista da compensação financeira de hidrelétricas e sua importância para o município de Paulo Afonso", in Juracy Marques, Alfredo Wagner e Luciano Menezes (orgs.), Barrando as Barragens: o Início do Fim das Hidroelétricas. Manaus: UEA Edições/PNCSA, 217-242.

FOUCAULT, Michel, 2014, On the Government of the Living: Lectures at the Collège de France 1979-1980. Londres, Palgrave Macmillan.

GOMES, Flavio, 1975, Transamazônica: a Redescoberta do Brasil. São Paulo: Livraria Cultura Editora.

HERZFELD, Michael, 2016, A Produção Social da Indiferença: Explorando as Raízes da Burocracia Ocidental. Petrópolis: Vozes.

LACERDA, Paula, 2014, Meninos de Altamira: Violência, "Luta” Política e Administração Pública. Rio de Janeiro: Garamond.

LIPSKY, Michael, 1980, Street-Level Bureaucracy: Dilemmas of the Individual in Public Services. Nova Iorque: Russell Sage Foundation.

NORTE ENERGIA, 2011 , Projeto Básico Ambiental. Usina Hidroelétrica Belo Monte. 
NORTE ENERGIA, 2013, Caderno de Preço Zona Urbana de Altamira. Usina Hidroelétrica Belo Monte.

PINHO, Vânia, e Assis da Costa OLIVEIRA (orgs.), 2013, Relatório Final do Diagnóstico Rápido Participativo: Enfrentamento da Violência Sexual contra Crianças e Adolescentes no Município de Altamira-PA. Altamira: s/ editora.

RIBEIRO, Gustavo Lins, 2008, “Poder, redes e ideologia no campo do desenvolvimento”, Novos Estudos CEBRAP, 80: 109-125.

ROJAS, Biviany, 2014, "(Des)cumprimentos das condicionantes socioambientais de Belo Monte”, in João Pacheco de Oliveira e Clarice Cohn (orgs.), Belo Monte e a Questão Indígena. Brasília, DF: ABA, 102-125.

SCOTT, James, 1998, Seeing Like a State: How Certain Schemes to Improve the Human Condition Have Failed. New Haven e Londres: Yale University Press.

SIGAUD, Lygia, 1986, "Efeitos sociais de grandes projetos hidroelétricos: as barragens de Sobradinho e Machadinho", Comunicação n. 9 do Programa de Pós-Graduação em Antropologia Social. Rio de Janeiro: Museu Nacional/Universidade Federal do Rio de Janeiro, 9: 1-36.

SOUZA LimA, Antonio Carlos de, 2002, Gestar e Gerir: Estudos para Uma Antropologia da Administração Pública no Brasil. Rio de Janeiro: Relume Dumará, núcleo de Antropologia da Política/UFRJ.

VIANNA JÚNIOR, Aurélio, 2018, “Grandes projetos, expansão do agronegócio e modernização compulsória no Rio São Francisco”, in Juracy Marques, Alfredo Wagner e Luciano Menezes (orgs.), Barrando as Barragens: o Início do Fim das Hidroelétricas. Manaus: UEA Edições/PNCSA, 15-42.

VILAÇA, Luiz, 2017, Costuras, Deslocamentos e Bricolagens: a Atuação de Procuradores do Ministério Público Federal no Caso de Belo Monte. Brasília: Universidade de Brasília, dissertação de mestrado apresentada ao programa de pós-graduação em Ciência Política.

ZACKA, Bernardo, 2017, When State Meets the Streets: Public Service and Moral Agency. Cambridge, MA, e Londres: Harvard University Press. 